\title{
İdiyopatik Normal Basınçlı Hidrosefali Tanısı ile Şant Uygulanan Hastaların Tedavi ve Gözlem Sonuçları
}

Treatment and Observation Results of Patients Undergoing Shunts with a Diagnosis of Idiopathic Normal Pressure Hydrocephalus

\author{
Özgür Şenol ${ }^{1}$, Emine Dağıstan², Zeliha Coşgun ${ }^{2}$, Melike Elif Kalfaoğllu², Yaşar Dağıstan ${ }^{1}$ \\ ${ }^{1}$ Bolu Abant Izzet Baysal Universitesi Tip Fakültesi, Beyin ve Sinir Cerrahisi AD \\ ${ }^{2}$ Bolu Abant Izzet Baysal Universitesi Tip Fakültesi, Radyoloji AD \\ Yazıșma Adresi / Correspondence: \\ Emine Dağıstan \\ Bolu Abant Izzet Baysal Universitesi Tip Fakültesi, Radyoloji AD 14280, Golkoy, Bolu, Türkiye \\ T: :+90374 2534656 E-mail: yemined@gmail.com \\ Geliş Tarihi/ Received : 11.12.2020 Kabul Tarihi / Accepted : 01.06.2021 \\ Orcid: \\ Özgür Şenol https://orcid.org/0000-0002-4106-5666 \\ Emine Dağıstan https://orcid.org/0000-0002-0202-8555 \\ Zeliha Coşgun https://orcid.org/0000-0003-1996-1568 \\ Melike Elif Kalfaoğlu https://orcid.org/0000-0003-1678-763X \\ Yasar Dağıstan https://orcid.org/0000-0002-1668-7850 \\ ( Sakarya Tip Dergisi / Sakarya Med J 2021, 11(2):388-394) DOI: 10.31832/smj.835351
}

\footnotetext{
$\ddot{O ̈ z}_{z}$

Amaç İdiyopatik normal basınçlı hidrosefali (iNPH) tanısı ile orta basınçlı ventriküloperitoneal (VP) ve lumboperitoneal (LP) şant uygulanan hastaların 3 ylllık takip sırasında klinik sonuçları ve şant tedavisinde karş̧laştı̆̆ımız problemleri sunmayı amaçladık.

Gereç ve Çalısmaya 2013 - 2017 tarihleri arasında Nöroloji ve Nöroşirurji Anabilim Dallarına başvuran, klinik ve radyolojik olarak iNPH olarak değerlendirilen hastalar retrospektif Yöntem olarak tarandı.VP ve LP şant uygulanan hastalarda başarı oranları ve komplikasyonları kayıt edildi.

Bulgular Değerlendirilen 26 hastanın 19 tanesine (\%73,1) VP sant, 7 tanesine (\%26,9) LP șant uygulandı. 5 hastaya (\%19) batın revizyonu, 2 hastaya (\%11) kranial revizyonu uygulandı. Cerrahi sonrası 1 hastada (\%5) subdural hematom geliști. 3 (\%11) hastada analjezik tedaviye yanıtlı, günler içerisinde düzelen baș ağrısı geliști. Hiçbir hastada şant enfeksiyonu, şant erezyonu, işitme kaybı, görme kaybı veya sistemik enfeksiyon gibi majör komplikasyon görülmedi.

Sonuç iNBH'de hastaların yaş ortalaması yüksek olmasından dolayı beyin atrofiside eşlik edebileceğinden hızlı beyin omurilik sıvısı (BOS)boşalımının kanamalara sebep olma riski göz önünde bulundurulmalıdır. Komplikasyon oranının daha düşük olması ve ayarlanabilir şantın manyetik ortamlardan çabuk etkilenmesinden dolayı öncelikle orta basınçlı VP șant ve ardından LP șant düșünülebilir

Anahtar İdiyopatik normal basınçlı hidrosefali; ventriküloperitoneal șant; lumboperitoneal șant Kelimeler

Abstract

Objective We aimed to present the clinical results of patients with idiopathic normal pressure hydrocephalus ( $N$ NPH) and medium pressure ventriculoperitoneal (VP) and lumboperitoneal (LP) shunts during the 3-year follow-up period and the problems we encountered in shunt treatment.

Materials Patients who applied to the Departments of Neurology and Neurosurgery between 2013 and 2017 and who were evaluated clinically and radiologically as iNPH were retrospectively screened. and methods Success rates and complications in patients who underwent VP and LP shunt were recorded.

Results VP shunt was applied to 19 (73.1\%) of 26 evaluated patients, and LP shunt was applied to 7 (26.9\%) of them. Abdominal revision was performed in 5 patients (19\%), and cranial revision was performed in 2 patients (11\%). Subdural hematoma developed in 1 patient (5\%) after surgery. $3(11 \%)$ patients developed headache responsive to analgesic treatment and resolved within days. Major complications such as shunt infection, shunt erosion, hearing loss, vision loss, or systemic infection were not observed in any patient.

Conclusion Since the average age of patients in $\mathrm{NBH}$ is high, it may accompany brain atrophy, the risk of rapid Cerebrospinal fluid (CSF) discharge causing bleeding should be considered. Since the complication rate is lower and the adjustable shunt is quickly affected by magnetic environments, firstly medium pressure VP shunt and then LP shunt can be considered.

Keywords Idiopathic normal pressure hydrocephalus; ventriculoperitonealshunt; lumboperitoneal shunt
} 


\section{GIIRIș}

İdiyopatik normal basınçı hidrosefali (iNPH) klinik bulguları açıklayacak başka bir neden olmaksızın, yürüyüş bozukluğu, kognitif bozukluk ve üriner inkontinansla karakterize, kranial görüntülemede ventriküler dilatasyonun izlendiği bir nörolojik tablodur. ${ }^{1}$ Tanı için yürüyüş bozukluğu ve ek bir klinik bulgunun olması gerekmektedir. ${ }^{2} \mathrm{Ge}$ leneksel olarak hastalığın klasik triadının ventriküler dilatasyonun periventriküler sinirlere bası yapması ile ortaya çıktığı düşünülse de son yıllarda yapılan çalışmalar artık maddelerin ekstrasellüler alandan beyin omurilik sıvısı (BOS) ile temizlenmesinde yetersizlik ile ilişkili olabileceğini düşündürmektedir., ${ }^{3,4}$ iNPH'nın sıklığı yüksektir ve 65 yaş üstü popülasyonda iNPH \%0,5 ila 2,9 düzeyindedir. ${ }^{5}$ Klinik bulgular ventriküloperitoneal (VP) ya da LP (lumboperitoneal) şant yerleştirilmesi ile potansiyel olarak geri döndürülebilir. ${ }^{6}$ Yapılan çalışmalarda iNPH hastalarında yaşam kalitesinin sağlıklı erişkinlerden daha düşük olduğu ve hastaların \%86'sında şantameliyatı ile yaşam kalitesinin normal popülasyonla neredeyse eş değere ulaştığı gösterilmiştir. $^{7}$

Bu çalışmada, iNPH tanısı ile orta basınçlı VP ve LP şant uygulanan hastaların 3 yıllık takip sırasında klinik sonuçları ve şant tedavisinde karşılaştığımız problemleri sunmayı amaçladık.

\section{GEREÇ ve YÖNTEMLER}

$\mathrm{Bu}$ çalışma Bolu Abant İzzet Baysal Üniversitesi klinik araştırmalar yerel etik kurul tarafından 24.11.2020 tarihinde onaylandı (Proje no: 2020-276 ). Çalışmamız Helsinki İlkeler Deklerasyonuna uyularak gerçekleştirilmiştir. Çalışmamız kesitsel tipte tanımlayıcı bir çalışma olup 2013 - 2017 tarihleri arasında Nöroloji ve Nöroşirurji Anabilim Dallarına başvuran, klinik ve radyolojik olarak iNPH olarak değerlendirilen yaşları 50-80 arasında (ortalama $64,2 \pm 3,2$ ) değişen 26 hasta (16 erkek, 10 kadın) ile yapıldı. iNPH tanısı iNPH Amerikan-Avrupa kılavuzuna göre konuldu. Tüm hastaların MMSE (Mini mental state examination) skorları, inkontinans varlığı, hipertansiyon, diya- betes mellitus, serebrovasküler hastalık ve kardiyovasküler hastalık gibi komorbiditelerin varlığı, uygulanan şantın türü, cerrahi sonrası gelişen majör ve minör komplikasyonları, batın ve/veya kranial revizyon varlığı kaydedildi. ${ }^{8,9}$ Yürüme ve mobiliteyi değerlendirmek için Timed "up and go" test kullanıldı. ${ }^{10}$

Tanı amaçlı olarak hastalara bilgisayarlı beyin tomografisi (BBT) ve beyin manyetik rezonas görüntüleme (MRG) yapıldı. Kranial görüntülemede hidrosefali tanısı frontal horn çapının bifrontal çapa bölünmesiyle elde edilen Evans oranı kullanılarak yapıldı. ${ }^{6}$ (Resim 1)

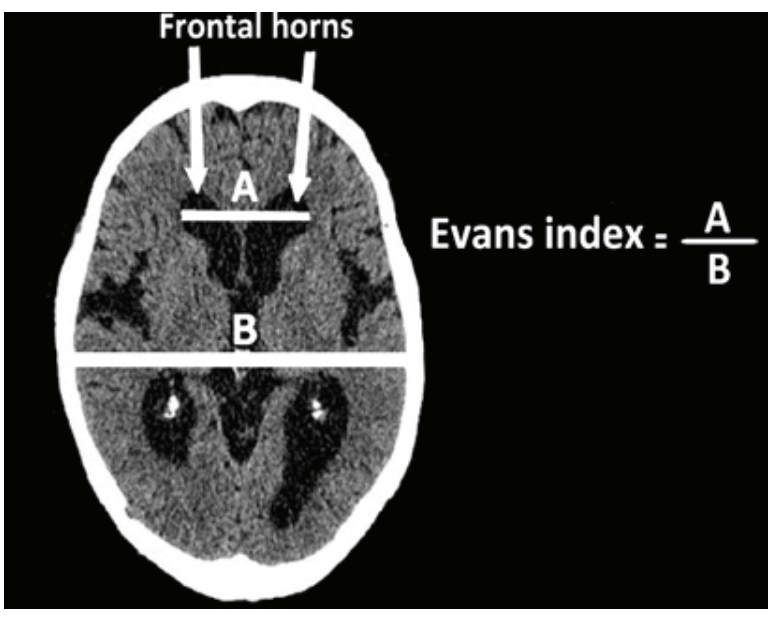

Resim 1: İdiyopatik Normal Basınçl Hidrosefali Tanısı ile Şant Uygulanan Hastalarm Beyin Tomografisindeki Evans Oranları

Klasik iNPH triadının birden fazla belirtisi (yürüme bozukluğu, bilişsel bozukluk, idrar kaçırma) olan, kranial görüntülemede (MR veya $\mathrm{BT}$ ) ventriküler dilatasyon bulgusu olan ve Evans indeksi> 0,3 olan, klinik semptomları açıklayacak altta yatan nörolojik veya nörolojik olmayan başka herhangi bir hastalık saptanmayan, kafa travması, subaraknoid kanama, konjenital hidrosefali, menenjit ve akuaduktus stenozu gibi ventriküler genişlemeyi açılayan bulguları olmayan hastalar çalışmaya dahil edildi.

\section{Cerrahi Prosedür}

Hastaların 19 tanesine orta basınçlı ventriküloperitone- 
al (VP) şant, 7 tanesine LP şant uygulandı. VP şantın sol frazier noktasından ventrikül ucu, sol alt kadrana da batın ucu gönderildi. Lumboperitoneal (LP) şant L4-5 lomber 4-5 intervertebral mesafesinden özel iğne ile omurga aralıklarından yapılan kesiden Beyin omurilik sıvısı (BOS) gelinceye kadar girildi. BOS gelince iğne içinden kateter gönderildi ve iğne çıkarılarak kateter içerde bırakıldı. Kateterin diğer ucu metal bir tünel açıcı ile cilt altından karındaki kesiye ulaştırıldı ve daha sonra bu uç peritona sokuldu. Tüm hastalar operasyon sonrasındaki 3 yıl boyunca nöroşirurji polikliniğinde düzenli aralıklarla takip edildi.

\section{BULGULAR}

Bu retrospektif çalışmada toplam 26 hasta çalışmaya dahil edildi. Çalışmaya dahil edilen hastaların demografik verileri tablo 1'de gösterildi.

\begin{tabular}{|l|c|}
\hline \multicolumn{2}{|l|}{ Tablo 1. İdiyopatik Normal Basınçlı Hidrosefali Tanısı ile Şant } \\
Uygulanan Hastaların Demografik Verileri \\
\hline Yaş & $64,2 \pm 3,2$ \\
\hline Cinsiyet & $\mathrm{n}(\%)$ \\
\hline Kadın & $16(61,5)$ \\
\hline Erkek & $10(38,5)$ \\
\hline Ek Hastalıklar & $\mathrm{n}(\%)$ \\
\hline Hipertansiyon & $11(\% 42)$ \\
\hline Serebrovasküler Hastalık & $4(\% 15)$ \\
\hline Obezite & $2(\% 7,7)$ \\
\hline Koroner arter Hastalığı & $1(\% 3)$ \\
\hline Diabetes mellitus & $8(\% 31)$ \\
\hline $\begin{array}{l}\text { Değerler: } \mathrm{n}=\text { hasta sayısı, } \mathrm{n}(\%), \text { ortalama } \\
\text { verilmiştir. }\end{array}$ & \\
\hline
\end{tabular}

İdiyopatik Normal Basınçlı Hidrosefali Tanısı ile Şant Uygulanan Hastaların Şant Cerrahi Sonrası Komplikasyonları tablo 2'de belirtildi. Lumboperitoneal şant uygulanan hastalarda abdominal revizyon fazla görüldü. Hiçbir hastada şant enfeksiyonu, şant erezyonu, işitme kaybı, görme kaybı veya sistemik enfeksiyon gibi majör komplikasyon görülmedi. Hiçbir hastamızda epileptik nöbet izlenmedi. Cerrahi sırasında, sonrasında veya takiplerde işlemle ilişkili veya ilişkisiz mortalite izlenmedi. Demansiyel bulgu- ları olan 12 hastanın takiplerinde MMSE skorlarında gerileme izlenmedi. Alzheimer Hastalığı ön tanısı olan bir hastanın MMSE skorunda değişiklik izlenmedi. Vasküler demansı olan iki hasta yürüme bozukluğu açısından cerrahi tedaviden anlamlı fayda gördü. Ancak takiplerinde bir hastada cerrahinin 8. ayında yürüme bozukluğu ve uyku hali yakınmaları gelişti. Ayarlanabilir şantla revizyon yapılarak basınç düşürüldü. Takiplerinde yürümede kısmi iyileşme görüldü. Ancak bilişsel ve davranışsal açıdan belirgin iyileşme izlenmedi. Obezitesi olan iki hastaya da karında şişlik yakınması ve ultrasonografide kistik lezyon görülmesi nedeniyle batın revizyonu yapıldı (Tablo 2).

\begin{tabular}{|c|c|c|}
\hline & $\begin{array}{c}\text { Ventriküloperitoneal } \\
\text { Şant } \\
\text { n }(\%)\end{array}$ & $\begin{array}{c}\text { lumboperitoneal } \\
\text { Şant } \\
\mathrm{n}(\%)\end{array}$ \\
\hline Hasta Sayısı & $19(\% 73,1)$ & $7(\% 26,9)$ \\
\hline \multicolumn{3}{|l|}{ Komplikasyonlar } \\
\hline $\begin{array}{l}\text { Abdominal } \\
\text { revizyon }\end{array}$ & $3(16)$ & $2(28)$ \\
\hline $\begin{array}{l}\text { Kranial } \\
\text { revizyon }\end{array}$ & $2(11)$ & \\
\hline $\begin{array}{l}\text { Subdural } \\
\text { hematom }\end{array}$ & $1(5)$ & 0 \\
\hline Şant enfeksiyon & 0 & 0 \\
\hline Şant erezyon & 0 & 0 \\
\hline İşitme Kaybı & 0 & 0 \\
\hline Epileptik Nöbet & 0 & 0 \\
\hline Baş ağrısı & $2(11)$ & $1(14)$ \\
\hline
\end{tabular}

\section{TARTIŞMA}

Yapılan çalışmalarda iNPH hastalarında yaşam kalitesinin sağlıklı erişkinlerden daha düşük olduğu ve hastaların \%86’sında şant ameliyatı ile yaşam kalitesinin normal popülasyonla neredeyse eş değere ulaştığı gösterilmiştir. ${ }^{7}$ $\mathrm{NPH}$, nadir görülen ancak tedavi edilebilir bir hastalıktır. Teşhisi zor olabilir çünkü bazı hastalıklar kognitif bozukluklara, idrar kaçırma ve yürüyüş fonksiyon bozukluğuna neden olabilir. İyi seçilmiş hastaları tedavi etmek klinik iyileşmeye neden olabilir, ancak şant prosedürünün risk- 
leri ve yararları tartılmalıdır. iNBH'de hastaların yaş ortalaması yüksek olmasından dolayı beyin atrofiside eşlik edebileceğinden hızlı BOS boşalımının kanamalara sebep olma riski göz önünde bulundurulmalıdır. Komplikasyon oranının daha düşük olması ve ayarlanabilir şantın manyetik ortamlardan çabuk etkilenmesinden dolayı öncelikle orta basınçlı V-P şant ve ardından L-P şant düşünülebilir.

İlk olarak 1965 yılında Adam's ve Hakim tarafından tanımlanmış olan iNPH sinsice ilerleyen bir yürüyüş bozukluğu idrar sıkıntısı ve ardından idrar kaçırma ve bilişsel bozukluk ve normal intrakranial basınç ile karakterizedir. ${ }^{11}$ $\mathrm{Bu}$ üç önemli klinik belirtinin BOS hipervolemi ayarında periventriküler frontal kortikal-bazal ganglionlar talamokortikal devrede bozulma nedeniyle meydana geldiği düşünülmektedir. ${ }^{12} \mathrm{NBH}$, idiopatik $\mathrm{NBH}$ ve sekonder $\mathrm{NBH}$ olmak üzere ikiye ayrılmaktadır. ${ }^{13}$ İdiopatik $\mathrm{NBH}$ daha ileri yaşlarda, 6. ve 8. dekatlar arasında, sekonder $\mathrm{NBH}$ ise daha genç yaşlarda görülmektedir. ${ }^{14}$ Oluşum mekanizmasını açıklamaya yönelik birçok teori bulunmaktadır. Sekonder grupta ise geçirilmiş subaraknoid kanama, kafa travması, beyin cerrahisi, menenjit gibi bir neden vardır. iNBH demansın tedavi edilebilir birkaç nedeni arasında bulunduğu için erken dönemde saptanması önemlidir. iNBH'de yürüyüş bozukluğu başlıca belirtidir ve kognitif belirtilerden daha önce çıkmaktadır. ${ }^{15}$ iNPH'deki yürüyüş fonksiyon bozukluğu geleneksel olarak "manyetik" veya "tutkal ayaklı” yürüyüş, olarak tanımlanmıştır. Bununla birlikte, yürüyüş anormalliği oldukça değişken olabilir ve muhtemelen belirli kortikal-bazal ganglionların-talamokortikal alanların bozulmasının bağlıdır. Bir iNPH ile ilişkili yürüyüşle uyumlu ortak özellikleri hastalar yürümeyi başlatmakta zorluk çekmektedir, küçük adımlar, geniş taban, dönüşlerde zorluk (genellikle bunu yapmak için birkaç adım atmak) merdiven inip çıkmada, sandalyeden kalkmada zorlanabilmektedirler. ${ }^{6}$ Bizim hastalarımızda benzer şekilde magnetik yürüyüş bozukluğu ve dönüşleri kısa ve sık adımlarla kontrolsüz yapılması ve oturup kalkmada zorluk mevcuttu. Bu hastaların bir kısmında Manyetik Rezonans Görüntüleme (MRG) de, T2 ağırlık- l1 görüntülerde kortikal-bazal ganglionlarda sinyal artışı bulunmaktaydı. Şant uygulanmasına yanıt verme olasılığı daha yüksek olan bu hastalar litaratüre uygun olarak uyguladığımız şant cerrahisinden belirgin fayda gördüler. ${ }^{16}$ iNPH'deki bilişsel bozukluk genellikle frontosubkortikal demans, olarak tanımlanır. ${ }^{17}$ Bazı yaygın bilişsel özellikler arasında psikomotorun yavaşlaması, dikkatin ve konsantrasyonun azalması, yönetici işlevlerinin bozulması ve ilgisizlik sayılabilir. Kortikal bulguların olmaması iNBH hastalığını Alzheimer hastalığından (AH) klinik olarak ayırmaya yardımcı olmaktadır. ${ }^{18}$ iNBH demansın tedavi edilebilir birkaç nedeni arasında bulunduğu için erken dönemde saptanması önemlidir. İleri evrede, uzun süreli semptomların bulunması durumunda tedaviye yanıt oranları daha düşük olmaktadır. ${ }^{19}$ Klinik olarak tanı koymada semptomların şiddetinde ve ilerleyiciliğinde kişisel farklılıklar olması tanıyı zorlaştırmaktadır. ${ }^{20}$

Bizim çalışmamızda Alzheimer ön tanısı olan hasta bilişsel olarak şant operasyonunda fayda görmedi. Ancak yürüme bozukluğu yakınması düzeldi. Bilişsel yakınmaları olan hastaların takiplerimiz süresince yaptı̆̆ımız minimental test sonucunda demans şikayetlerinde ilerleme olmadığını gözlendi. Her ne kadar üriner inkontinans 3 ana bulgusu içinde olsa da NBH hastalarında en az görülen bulgudur. İdiyopatik iNPH'nin idrar semptomları, frontal lob inkontinansın orijinal klinik tarifiyle uyumludur. Hastalığın seyrinde başlangıçta hastalarda idrara sıkışma hissi ve idrar sıklığında artış görülmekte ancak ilerleyen dönemlerde belirgin üriner inkontinans görülebilmektedir. ${ }^{21}$ Hastalar1mızın bir kısmında yetişememe ve idrar kaçırma şikayetleri vardı ürolojik ultrasonografik inceleme sonrası rezidü idrar tespit edildi. Postoperatif nöbet insidansı \%3 ile 11 arasında değişmektedir bildirilmiştir. ${ }^{22-24}$ Bizim olgu takiplerimizde hiçbir hastada nöbet gelişmedi.

İleri serebrovasküler hastalığı olan hastalar, şant cerrahisine yanıtları düşük olmakla işlemden bir miktar fayda sağlayabilirler. ${ }^{25}$ Şant cerrahisi geçiren $\mathrm{NBH}$ olgularının \%50'sinden azında klinik olarak semptomlarda gerileme 
mevcuttur. Bazı serilerde ise bu oran \%10-90 arasında değişmektedir. ${ }^{26}$ iNPH'de şant cerrahisine rağmen bazen kısa bir iyilik halinden sonra nörolojik düşüş devam edebilir bu kötüleşmenin komorbid koşulların ilerlemesi neticesinde oluştuğu yapılan birçok çalışma ile gösterilmiştir. ${ }^{27,28}$ Bizim çalışmamızda iki hastada vasküler demans ön tanısı mevcuttu. Her iki hasta da erken dönemde cerrahiden anlamlı fayda görürken, hastalardan birinin takiplerinde yürüyüş ve bilişsel kötüleşme izlendi. Bu bulgular, iNPH'de uygulanan bir şant cerrahisinin hastalığın ilerlemesini her zaman durduramayacağını ya da komorbid koşulların ilerleyebileceğini ve nörolojik tabloyu kötüleştireceğini göstermektedir. Bununla birlikte, birkaç yıllık geçici düzelmeler bile, bu kişiler ve yakınları için yaşam kalitesinde önemli bir fark yaratabilir.

Tedavi yöntemlerinden biri de VP ve LP şant yerleştirilmesidir. Lomber ponksiyon ile yaklaşık 40-50 ml BOS boşaltılması sonrası özellikle yürüme bozukluğu semptomlarında düzelme olması şant cerrahisinden yarar görme ihtimalini arttırmaktadır. Test sonucu faydalanma oranları \%73-100 arasındadır. Ancak sensitivitesi düşüktür ve \%26-61 arasında değişmektedir. BOS boşaltımı sonrası semptomların gerilememesi iNBH tanısını dışlamamaktadır. $^{29}$ iNPH'yi yönetmek zordur, çünkü şant ile yapılan cerrahi komplikasyonlar sıktır. Gecikmiş morbidite, enfeksiyon, nöbetler, şant tıkanması, subdural sıvı toplanması, aşırı BOS boşalma, baş ağrıları ve şant yetersizliği ortaya çıkabilir. Kalıcı morbidite açısından bakıldığında en önemli komplikasyon subdural kanamadır. ${ }^{22}$ iNPH için bir şanttan sonra subdural kanama insidansı tam olarak bilinmemektedir ve değerler \%2 ila 17 arasında değişmektedir. $^{26,28,30,31} 2013$ yılında Toma ve ark. NPH ile ilgili yapılan çalışmalar gözden geçirilmiş ve NPH cerrahi sonrasında komplikasyon oranları mortalite \% 0.2, subdural kanama $\%$ 4,5 intrakranial kanama \% 0.2, enfeksiyon \% 3.5 ve revizyonlar \% 13 olarak özetlenmiş. ${ }^{32}$ Bir diğer retrospektif çalışmada intraserebral hematom insidansı $\% 3$ bulunmuştur. ${ }^{33}$ Orta basınçlı V-P şant kullandığımız 1(\%3) hastada subdural kanama gelişti, LP şant uygulanan bir hastada kontrol filmlerinde slit ventrikül gelişti, şikâyetleri çok belirgin olmadığı için revizyon yapılmadı ve takibe devam edildi. Yukardaki çalışmalar ve diğer bir çok çalışmalarda görülmektedir ki iNBH hastalarında uygulanan VP şant cerrahisinde ;ayarlanabilir, orta basınç ve düşük basınçlı VP şantların hepsini VP şant üst başlığı altında tanımlamışlar ve komplikasyonları VP şant cerrahi sonuçları olarak bildirmişler. subdural efüzyonların görülme sıklığı şant drenajının derecesi ile ilişkili olduğu ve bu nedenle düşük ve orta basınçlı valflerde görülme sıklığı daha yüksek olduğu belirtilmiştir. ${ }^{25}$ Bizim çalışmamızda literatürün aksine orta basınçlı V-P şant cerrahisinde bu oranın daha düşük olduğunu gözlemledik. Bu oranların literatüre göre düşük olmasını ileri yaş hastalarda beyin atrofisinide göz önüne aldığımızda ilk tercihimiz daha kontrollü BOS drenajı sağladığından ve ayarlanabilir VP şant gibi magnetik ortamlardan etkilenmediğinden orta basınçlı V-P şantdır. Bizim şant revizyon oranımız literatürdeki çalışmalarla benzer bulundu. ${ }^{2,34}$

Ventrikülo peritoneal şant ameliyatlarında ventriküler uç tıkanması en sık rastlanan revizyon sebebidir ve tüm mekanik tıkanıklıkların \%63,2'sini oluşturmaktadır. ${ }^{35}$ Bizim çalışmamızda ventriküler uç tıkanma oranı \%11 (2 hasta) ile litaratüre göre düşük bulunmuştur. Ventriküloperitoneal şant tıkanmalarının diğer nedeni şant kateterinin distal ucunun tıkanmasıdır. Özellikle batın şikayetleri ile gelen V-P şantlı hastalara derhal batın ultrasonografisi yapılmalıdır. ${ }^{36,37}$ Olgularda bizim çalışmamızdaki periton kateter tıkanma sebepleri: kateterin periton üzerinde kalması, abdominal psödokist oluşmasıdır. Batın revizyon oranımızın biraz yüksek olmasının sebebi periton ucu trokar kullanılarak yerleştirilirken periton üzerinde kalmış olabileceğimizi düşünmekteyiz. Açık cerrahi ile periton ucunu gönderdiğimiz 12 hastanın ikisinde obezite mevcuttu ve bu hastada pösodokist gelişti. Malm ve ark. prospektif bir çalışmada şant uygulanmış hastalarda mortalite oranını\% 2 olarak bildirmişlerdir. ${ }^{28}$ Bizim 3 yıllık takiplerimizde mortalite görülmedi. Bu durumun takip süresinin kısa olması ile ilişkili olabileceği düşünüldü. Ayarlanabi- 
lir ve düşük basınçlı şantlarda daha çok karşımıza çıkan komplikasyonlar arasında, işitme kaybı, kulak çınlaması, okülomotor paralizileri ve baş ağrısı da bulunabilir. Tüm bu yakınmalar basınç ayarı değiştirilerek gerileyebilmektedir. ${ }^{38-40}$ Bizim kullandığımız orta basınçlı VP şant sonrasında hastalarımızda yukarıda sıralanan diğer şikayetler görülmedi. VP şantın batın ucuna gelen BOS’un batından emilimi ile ilgili komplikasyonlar görülebilir. Önceden yapılan batın ameliyatları sonucu oluşan peritonit ve peritoneal adezyonlar BOS emilimini engelleyebilir, bu yüzden şant cerrahi öncesinde bu tür bir öykü olup olmadığının değerlendirilmesi önemlidir. Çünkü emilim yetersizliğine sebep olabilir. Şiddetli kabızlık ve trunkal obesite VP şantın batın komplikasyonları açısında risk oluşturur. ${ }^{41-44}$ Bizim çalışmamızda da obezitesi olan iki hastanın her ikisine batında kistik lezyon gelişmesi nedeniyle batın revizyonu yapıldı. Çalışma tasarımı körleme içermediğinden hastaları opere eden ve değerlendiren beyin cerrahları ve nörologlar muhtemel bir cerrahi fayda beklentisinin farkındaydi.

VP ve LP şant hastalarının postoperatif dönemde sağlıkla ilişkili yaşam kalitesi üzerindeki uzun süreli etkilerini daha sonraki bir çalışmada ele almak için mevcut çalışmada değerlendirmedik.

\section{SONUÇ}

NPH, nadir görülen ancak tedavi edilebilir bir hastalıktır. Teşhisi zor olabilir çünkü bazı hastalıklar kognitif bozukluklara, idrar kaçırma ve yürüyüş fonksiyon bozukluğuna neden olabilir. İyi seçilmiş hastaları tedavi etmek klinik iyileşmeye neden olabilir, ancak şant prosedürünün riskleri ve yararları tartılmalıdır. iNBH'de hastaların yaş ortalaması yüksek olmasından dolayı beyin atrofiside eşlik edebileceğinden hızlı BOS boşalımının kanamalara sebep olma riski göz önünde bulundurulmalıdır. Komplikasyon oranının daha düşük olması ve ayarlanabilir şantın manyetik ortamlardan çabuk etkilenmesinden dolayı öncelikle orta basınçlı V-P şant ve ardından L-P şant düşünülebilir
Çalışma Bolu Abant İzzet Baysal Üniversitesi klinik araştırmalar yerel etik kurul tarafından 24.11.2020 tarihinde onaylandı (Proje no: 2020-276 ).

Çıkar çatışması yoktur

\section{Mali açıklama}

$\mathrm{Bu}$ çalışma herhangi bir kuruluş tarafından finanse edilmemiştir. 
Sakarya Tip Dergisi 2021;11(2):388-394

ŞENOL ve Ark., Hidrosefali Hastalarında Şant Cerrahisi Sonuçları

\section{Kaynaklar}

1. Martín-Láez R, Valle-San Román N, Rodríguez-Rodríguez E, Marco-de Lucas E, Blanco JB, Vázquez-Barquero A. Current concepts on the pathophysiology of idiopathic chronic adult hydrocephalus: Are we facing another neurodegenerative disease? Neurología (English Edition). 2018;33(7) 449-458.

2. Shprecher D, Schwalb J, Kurlan R. Normal pressure hydrocephalus: diagnosis and treatment. Curr Neurol Neurosci Rep. 2008;8(5):371.

3. Silverberg GD, Messier AA, Miller MC, Machan JT, Majmudar SS, Stopa EG, et al. Amyloid efflux transporter expression at the blood-brain barrier declines in normal aging. J Neuropathol Exp Neurol. 2010;69(10):1034-1043.

4. Silverberg GD, Miller MC, Messier AA, Majmudar S, Machan JT, Donahue JE, et al. Amyloid deposition and influx transporter expression at the blood-brain barrier increase in normal aging. J Neuropathol Exp Neurol. 2010;69(1):98-108.

5. Tullberg M, Persson J, Petersen J, Hellström P, Wikkelsø C, Lundgren-Nilsson Å. Shunt surgery in idiopathic normal pressure hydrocephalus is cost-effective-a cost utility analysis. Acta Neurochir (Wien). 2018;160(3):509-518.

6. Graff-Radford NR, Jones DT. Normal pressure hydrocephalus. Continuum: Lifelong Learning in Neurology. 2019;25(1):165-186.

7. Petersen J, Hellström P, Wikkelsø C, Lundgren-Nilsson Å. Improvement in social function and health-related quality of life after shunt surgery for idiopathic normal-pressure hydrocephalus. J Neurosurg. 2014;121(4):776-784.

8. Tombaugh, Tom N., and Nancy J. McIntyre. "The mini-mental state examination: a comprehensive review." Journal of the American Geriatrics Society 40.9 (1992): 922-935

9. Relkin N, Marmarou A, Klinge P, Bergsneider M, Black PM. Diagnosing idiopathic normal-pressure hydrocephalus. Neurosurgery. 2005;57(suppl_3): 4-16.

10. Podsiadlo D, Sandra R. "The timed "Up \& Go": a test of basic functional mobility for frail elderly persons." Journal of the American geriatrics Society 39.2 (1991): 142-148.

11. Parkkola R, Komu M, Kotilainen E, Valtonen S, Thomsen C, Gideon P. Cerebrospinal fluid flow in patients with dilated ventricles studied with MR imaging. Eur Radiol. 2000;10(9):1442-1446.

12. Curran T, Lang AE. Parkinsonian syndromes associated with hydrocephalus: case reports, a review of the literature, and pathophysiological hypotheses. Movement disorders: official journal of the Movement Disorder Society. 1994;9(5):508-520.

13. Bradley WG. Normal pressure hydrocephalus: new concepts on etiology and diagnosis. American Journal of Neuroradiology. 2000;21(9):1586-1590.

14. Krauss J, Regel J. The predictive value of ventricular CSF removal in normal pressure hydrocephalus. Neurol Res. 1997;19(4):357-360.

15. Boon AJ, Tans JT, Delwel EJ, Egeler-Peerdeman SM, Hanlo PW, Wurzer HA, et al. Dutch Normal-Pressure Hydrocephalus Study: the role of cerebrovascular disease. J Neurosurg. 1999;90(2):221-226.

16. Bugalho P, Guimarães J. Gait disturbance in normal pressure hydrocephalus: a clinical study. Parkinsonism Relat Disord. 2007;13(7):434-437.

17. Picascia M, Zangaglia R, Bernini S, Minafra B, Sinforiani E, Pacchetti C. A review of cognitive impairment and differential diagnosis in idiopathic normal pressure hydrocephalus. Funct Neurol. 2015;30(4):217

18. Savolainen S, Paljärvi L, Vapalahti M. Prevalence of Alzheimer's disease in patients investigated for presumed normal pressure hydrocephalus: a clinical and neuropathological study. Acta Neurochir (Wien). 1999;141(8):849-853.

19. Petersen RC, Mokri B, Laws ER. Surgical treatment of idiopathic hydrocephalus in elderly patients. Neurology. 1985;35(3):307

20. Gallia GL, Rigamonti D, Williams MA. The diagnosis and treatment of idiopathic normal pressure hydrocephalus. Nature Reviews Neurology. 2006;2(7):375.

21. Andrew J, Nathan P. Lesions of the anterior frontal lobes and disturbances of micturition and defaecation. Brain. 1964;87(2):233-262.

22. Larsson J, Israelsson H, Eklund A, Malm J. Epilepsy, headache, and abdominal pain after shunt surgery for idiopathic normal pressure hydrocephalus: the INPH-CRasH study. J Neurosurg. 2018;128(6):1674-83.
23. Laws Jr ER, Mokri B. Occult hydrocephalus: Results of shunting correlated with diagnostic tests. Neurosurgery. 1977;24(CN_suppl_1):316-333.

24. Hughes C, Siegel B, Coxe W, Gado M, Grubb R, Coleman R, et al. Adult idiopathic com municating hydrocephalus with and without shunting. J Neurol Neurosurg Psychiatry. 1978;41(11):961-971.

25. Boon AJ, Tans JT, Delwel EJ, Egeler-Peerdeman SM, Hanlo PW, Wurzer HA, et al. Dutch Normal-Pressure Hydrocephalus Study: randomized comparison of low-and medium-pressure shunts. J Neurosurg. 1998;88(3):490-495.

26. Bergsneider M, Black PM, Klinge P, Marmarou A, Relkin N. Surgical management of idiopathic normal-pressure hydrocephalus. Neurosurgery. 2005;57(suppl_3):29-39.

27. Greenberg J, Shenkin H, Adam R. Idiopathic normal pressure hydrocephalus--a report of 73 patients. J Neurol Neurosurg Psychiatry. 1977;40(4):336-341.

28. Malm J, Kristensen B, Stegmayr B, Fagerlund M, Koskinen L-O. Three-year survival and functional outcome of patients with idiopathic adult hydrocephalus syndrome. Neurology. 2000;55(4):576-578.

29. Marmarou A, Bergsneider M, Klinge P, Relkin N, Black PM. The value of supplemental prognostic tests for the preoperative assessment of idiopathic normal-pressure hydrocephalus. Neurosurgery. 2005;57(suppl_3):17-28.

30. Benzel EC, Pelletier AL, Levy PG. Communicating hydrocephalus in adults: prediction of outcome after ventricular shunting procedures. Neurosurgery. 1990;26(4):655-660.

31. Krauss JK, Droste DW, Vach W, Jens P R, Orszagh M, Borremans JJ, et al. Cerebrospinal fluid shunting in idiopathic normal-pressure hydrocephalus of the elderly: effect of periventricular and deep white matter lesions. Neurosurgery. 1996;39(2):292-300.

32. Toma AK, Papadopoulos MC, Stapleton S, Kitchen ND, Watkins LD. Systematic review of the outcome of shunt surgery in idiopathic normal-pressure hydrocephalus. Acta Neurochir (Wien). 2013;155(10):1977-1980.

33. Black P, Ojemann R, Tzouras A. CSF shunts for dementia, incontinence, and gait disturbance. Clin Neurosurg. 1985;32:632-651.

34. Raftopoulos C, Massager N, Baleriaux D, Deleval J, Clarysse S, Brotchi J. Prospective analysis by computed tomography and long-term outcome of 23 adult patients with chronic idiopathic hydrocephalus. Neurosurgery. 1996;38(1):51-59.

35. Sainte-Rose C, Piatt J, Renier D, Pierre-Kahn A, Hirsch J, Hoffman H, et al. Mechanical complications in shunts. Pediatr Neurosurg. 1991;17(1):2-9.

36. Schmidt K, Gjerris F, Osgaard O, Hvidberg EF, Kristiansen JE, Dahlerup B, et al. Antibiotic prophylaxis in cerebrospinal fluid shunting: a prospective randomized trial in 152 hydrocephalic patients. Neurosurgery. 1985;17(1):1-5.

37. Haralampopoulos F, Iliadis H, Karniadakis S, Koutentakis D. Invasion of a peritoneal catheter into the inferior vena cava: report of a unique case. Surg Neurol. 1996;46(1):21-22.

38. Lim HW, Shim BS, Yang CJ, Kim JH, Cho YH, Cho YS ve diğerleri (2014) Hidrosefali hastalarının iletişiminde ventriküloperitoneal șantı takiben işitme kaybı: bir pilot çalıșma. Laringoskop 124: 1923-1927

39. Miyazaki Y, Tomii M, Sawauchi S, Ikeuchi S, Yuki K, Abe T (1997) Ventrikülo-peritoneal şant prosedüründen sonra beyin omurilik sivisının aşırı drenajının neden olduğu bir ișitme kaybı vakast. Shinkei Geka yok 25: 367-371

40. Stoeckli SJ, Bohmer A (1999) Hidrosefali için şant yerleștirildikten sonra kalıcı iki tarafl ișitme kaybı. Vaka raporu. J Neurosurg 90: 773-775

41. Shimizu S, Mochizuki T, Nakayama K, Fujii K. Visual field defects due to a shunt valve migrating into the cranium. Acta Neurochir (Wien). 2002;144(10):1055-1060.

42. Chung J-J, Yu J-S, Kim JH, Nam SJ, Kim M-J. Intraabdominal complications secondary to ventriculoperitoneal shunts: CT findings and review of the literature. American Journal of Roentgenology. 2009;193(5):1311-1317.

43. Kanai M, Kawano K, Uehara S. Upward migration of the LP shunt catheter into the cranial base. Osaka City Med J. 1999;45(2):123-127.

44. Kariyattil R, Steinbok P, Singhal A, Cochrane DD. Ascites and abdominal pseudocysts following ventriculoperitoneal shunt surgery: variations of the same theme. J Neurosurg Pediatr. 2007;106(5):350-353. 